Preprints of the

Max Planck Institute for

Research on Collective Goods

Bonn 2007/10

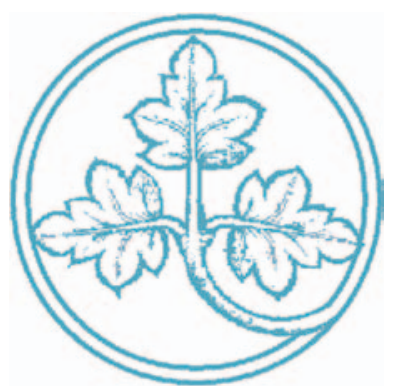

Purchase Decisions with Non-linear Pricing Options under Risk - Experimental Evidence

Frank P. Maier-Rigaud

Martin Beckenkamp

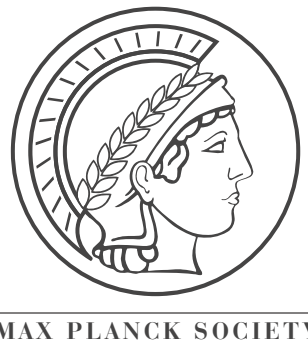




\section{Purchase Decisions with Non-linear Pricing Options under Risk - Experimental Evidence}

Frank P. Maier-Rigaud / Martin Beckenkamp

August 2007 


\title{
Purchase Decisions with Non-linear Pricing Options under Risk - Experimental Evidence*
}

\author{
Frank P. Maier-Rigaud ${ }^{\dagger} \quad$ Martin Beckenkamp ${ }^{\ddagger}$
}

August 20, 2007

\begin{abstract}
We experimentally investigate purchase decisions with linear and nonlinear pricing under risk. The experiment is based on a single period stochastic inventory problem with endogenous cost. It extends classic binary lottery experiments to test standard decision theoretic predictions concerning purchasing behavior in a rebate and a discount scheme. We investigate to what extent customers continue to purchase under two mathematically isomorph formats of non-linear schemes even if switching to a linear pricing scheme is optimal. Our results indicate that rebate and discount schemes exert a significant attraction on customers. Given the increased role of non-linear pricing schemes, systematic deviations from optimal behavior are an important element in the design of such schemes and may raise consumer protection and competition questions. We discuss how our results can be explained by decision heuristics.
\end{abstract}

JEL-Classifications: C91, D81, D40, L42.

Keywords: rebate, discount, linear price, newsvendor problem, stochastic inventory problem, lotteries, risk preferences.

*This paper is based on a contribution for the Competition Law Scholars Forum (CLaSF) from which financial support is gratefully acknowledged. We thank Stefan Bechtold, Christoph Engel, Hendrik Hakenes, Martin Hellwig, Hans Normann, Reinhard Selten, Michael Stratmann, seminar participants at the University of Bonn and the 2006 EARIE Conference in Amsterdam for comments on an earlier version of this paper.

${ }^{\dagger} B$ onnEconLab, Laboratory for Experimental Economics, University of Bonn, Germany; Max Planck Institute for Research on Collective Goods, Bonn, Germany; European Commission, Directorate General Competition, Policy and Strategic Support Directorate, Brussels, Belgium; e-mail: maier-rigaud@microeconomics.de. The views expressed are those of the author and not of the European Commission.

${ }^{\ddagger}$ Max Planck Institute for Research on Collective Goods, Bonn, Germany, e-mail: beckenk@coll.mpg.de. 


\section{Introduction}

Standard economic theory suggests that customers should be indifferent to the format of a price reduction. In particular this implies that one would expect a customer to switch independently of the scheme in use from one pricing scheme to another (one supplier to another) as long as there is at least an expected reduction in the effective purchase price. The recent surge in the use of rebates, discounts, bonus and point schemes implemented by retailers but also observed in other levels of the production chain begs the question of whether traditional economic explanations do fully account for the increased usage of non-linear pricing methods. An understanding of potential behavioral reasons for using such pricing schemes may not only be relevant for their design, but also for consumer protection and competition policy issues. ${ }^{1}$

This paper focuses on the analysis of behavioral responses triggered by rebate and discount schemes in a decision theoretic context similar to the classic lottery experiments conducted by Kahnemann and Tversky. In our analysis we consider two mathematically identical formats of such schemes. In the "discount" format a reduced price is granted from the start and the discount has to be reimbursed at the end of a reference period if a quantity threshold has not been reached. In the "rebate" format a reduced price is granted retroactively once a quantity threshold has been reached. The effects of these two formats are experimentally tested by confronting participants with different price schemes in a formally identical risky decision-making environment. ${ }^{2}$ The discount and rebate schemes are contrasted to a conventional linear price scheme.

\footnotetext{
${ }^{1}$ In competition policy for instance, one of the most controversial aspects of the recent review of the European Commissions approach to abuse of dominance under Article 82 ECT concerns potential foreclosure effects in rebate schemes. See Beckenkamp and Maier-Rigaud (2006) for an experimental discussion of rebate schemes in the context of Article 82 ECT. A more general discussion of the antitrust issues surrounding rebate schemes can be found in Maier-Rigaud (2006).

${ }^{2}$ Although rebate and discount schemes need not be formally identical (such as for example under discounting) our experiment is designed so that both schemes are isomorph.
} 
Of relevance to this paper is the extensive literature in operations research on what is called the newsvendor problem, i.e. the problem of determining the expected profit maximizing stocking decision under stochastic demand of a product that becomes obsolete at the end of a single period. ${ }^{3}$ The optimal solution is characterized by a balance between expected cost of understocking and the expected cost of overstocking. The newsvendor problem has also recently been analyzed experimentally. ${ }^{4}$ The main result of the experimental literature is that procurement quantities for low profit products were higher than expected profit maximizing quantities while orders for high profit products were lower than expected profit maximizing quantities.

Also related to our study is the paper by Eckel and Grossman (2003) analyzing different formats for charitable contributions. They report much higher charity receipts under a matching condition, where the experimenter matched any individual contribution at a preannounced rate than under a mathematically equivalent rebate condition where a portion of the contribution was paid back. Davis and Millner (2005) similarly focus on the effects of changes in the format of identical prices by offering chocolate bars under a rebate and a matching condition. They find that participants purchase significantly more chocolate bars under the matching condition, confirming the result by Eckel and Grossman $(2003) .^{5}$

The paper is organized as follows. Section 2 discusses rebate, discount and linear pricing schemes in a simple vertical (upstream producer, downstream retailer) relationship. Two hypotheses for the experimental results are considered: The

\footnotetext{
${ }^{3}$ The newsvendor problem is the fundamental building block of stochastic inventory theory. See for instance Arrow et al. (1951) or Mills (1959). Overviews can be found in Porteus (1990) and Petruzzi and Dada (1999).

${ }^{4}$ See Schweitzer and Cachon (2000), Brown and Tang (2000), Bolton and Katok (2005), Lurie and Swaminathan (2005), Ben-Zion et al. (2005), and Katok et al. (2006).

${ }^{5}$ See also Davis (2006), Eckel and Grossman (2006), and Davis et al. (2005). Karlan and List (2006) show that the offer to match contributions to a non-profit organization increases the likelihood and amount an individual donates in a field experiment.
} 
risk neutral maximization of expected profits and boundedly rational behavior as described for instance by prospect theory. Section 3 describes the experimental design, the hypotheses and the experimental results and section 4 concludes.

\section{Theoretical Background}

\subsection{Rebate, discount and linear pricing schemes}

Consider two upstream firms that produce a homogenous product at marginal cost $c$. The product is bought by a downstream retailer, that sells the good to final consumers. ${ }^{6}$ The upstream firms are referred to as $A$ and $B$. Denote by $T_{i}\left(q_{i}\right)$ the downstream firm's payment to upstream firm $i$ depending on the amount of units $q_{i}$ bought.

The upstream firm $A$ offers a rebate scheme, that is, $T_{A}\left(q_{A}\right) \equiv w q_{A}$ if $q_{A}<\bar{q}$ and $(1-\alpha) w q_{A}$ otherwise, where $w>0, \alpha \in(0,1)$ and $q_{A} \equiv \sum_{t=1}^{\tau} q_{A t}$, where $\tau$ denotes the final subperiod of the reference period. In this scheme, the downstream firm's average per unit price and marginal price equals $w$ at the end of $\tau$ if $q_{A}<\bar{q}$ units are purchased and $(1-\alpha) w$ otherwise. Since $\alpha>0$ the downstream firm is rewarded for purchasing at least $\bar{q}$ units. This implies that firm $A$ uses a rebate scheme where $\alpha$ is the percentage discount off the list price $w$ once $\bar{q}$ units have been bought. ${ }^{7}$

The upstream firm B in contrast offers a conventional price scheme, i.e. a linear pricing schedule implying a cost of $T_{B}\left(q_{B}\right) \equiv v q_{B} \forall q_{B} \geq 0$ for the downstream firm, where $q_{B} \equiv \sum_{t=1}^{\tau} q_{B t}$.

\footnotetext{
${ }^{6}$ Although it is rather standard to treat firms as individual decision makers and we will also do so in the theoretical as well as experimental part of the paper, it is still noteworthy that typically, a corporate decision making process underlies the behavior of the firm.

${ }^{7}$ Note that from a modelling perspective the pricing behavior of the upstream firms is the result of a profit maximizing calculus based on behavior downstream (retailer and final consumers). We neither model this vertical relationship nor competition upstream explicitly because it unnecessarily complicates the exposition without adding any particular insight to the question at hand.
} 
Consider the following variation to firm $A^{\prime} s$ pricing strategy that we refer to as discount scheme. An upstream firm $C$ may offer a discount price schedule $T_{C}\left(q_{C}\right) \equiv(1-\alpha) w q_{C}+F\left(q_{C}\right)$ if $q_{C}<\bar{q}$ and $(1-\alpha) w q_{C}$ otherwise, where $q_{C} \equiv$ $\sum_{t=1}^{\tau} q_{C t}$. This scheme is mathematically equivalent to the rebate scheme if $F\left(q_{C}\right)=$ $\alpha w q_{C} \forall q_{C}$. The only difference is that the reduced price $(1-\alpha) w q_{C}$ is paid from the first unit on and $F\left(q_{C}\right)$ is only paid if $q_{C}<\bar{q}$ at the end of $\tau .^{8}$

The downstream firm buying the good incurs only the cost of its purchases from the upstream firm(s) when it purchases $q_{i}>0$ units of the good. Let $p$ denote the retail price and $q_{t}(p, X)$ the consumers demand function with $q_{t}(p, X) \geq 0$ $\forall p, X$, where $X \sim N(\mu, \sigma)$ is a censored normally distributed (i.e. an approximately normally distributed) random variable cut at zero with a mean of $\mu$ and a standard deviation of $\sigma .^{9}$

The upstream firms profits are given by $\pi_{i}^{u} \equiv T_{i}\left(q_{i}\right)-c q_{i}$ and the downstream firm profit is given by $\pi^{d} \equiv \sum_{t=1}^{\tau} \pi_{t}^{d}$, where $\pi_{t}^{d}$ is given by:

$$
\pi_{t}^{d} \equiv \begin{cases}q_{t}(p, x) p-\sum_{i \in\{A, B\}} T_{i}\left(q_{i}\right) & \text { if } s_{t}+\sum_{i \in\{A, B\}} q_{i} \geq q_{t}(p, x) \\ p\left(s_{t}+\sum_{i \in\{A, B\}} q_{i}\right)-\sum_{i \in\{A, B\}} T_{i}\left(q_{i}\right) & \text { otherwise. }\end{cases}
$$

The level of stock at time $t$ is denoted by $s_{t} \cdot{ }^{10}$ Let $E\left(p^{*}\right)$ denote the expected profit maximizing price and $E(q) \equiv E\left(q_{t}\left(p^{*}, X\right)\right)$ the corresponding expected profit maximizing quantity.

Based on the price scheme information of the upstream firms and the demand function, the downstream firm calculates its expected profit maximizing price.

\footnotetext{
${ }^{8}$ Note that due to this isomorphism we will be able to concentrate on rebate schemes in the following theoretical exposition. All results directly apply to discount schemes as well.

${ }^{9}$ The corresponding probability density function is given by $f(x)$. Note that demand in each subperiod is therefore not only dependent on price but also on the normally distributed random term $X$ whose realization is denoted by $x$.

${ }^{10} s_{0} \equiv 0$ and $s_{t+1} \equiv \sum_{i \in\{A, B\}} q_{i t}+s_{t}-q_{t}(p, x)$.
} 
Given that price, it can determine the corresponding expected quantity that final consumers will buy and order accordingly. We consider the case where pricing of the downstream retailer exerts some inertia, that is, for example, due to menu cost, prices are fixed at the beginning of the reference period for the whole period. ${ }^{11}$ Ordering decisions can, however, be taken at least twice during the reference period.

We consider the reference period to be divided into $\tau$ subperiods, with subperiod $t \in\{1, \ldots, \tau\}$. The demand in each subperiod $q_{t}\left(p^{*}, X\right)$ is a random variable from one and the same random process and we assume that the demand in each subperiod is independent from each other. This implies that we consider the special case where the cumulated expected sales in each subperiod increase linearly and proportionally in time. ${ }^{12}$

\subsection{Risk neutral maximization of expected profits}

We are now interested in the question under what conditions it is profit maximizing for the downstream firm to switch from supplier $A$ or $C$ to supplier $B$. In order to simplify we consider the situation in the $\tau^{\prime}$ th subperiod with $v=(1-\alpha) w$, where the retailer has already bought $\sum_{t=1}^{\tau-1} q_{t}^{o}$ units, sold $\sum_{t=1}^{\tau-1} q_{t}$ units and therefore holds a stock of $s_{\tau}=\sum_{t=1}^{\tau-1}\left(q_{t}^{o}-q_{t}\right)$ units. $^{13}$ In that case, $\hat{q}_{\tau} \equiv \bar{q}-\sum_{t=1}^{\tau-1} q_{t}$ units would need to be bought to reach a purchase quantity equal to the threshold.

In order to determine under what constellation it is optimal to leave the rebate scheme, we need to calculate the optimal quantity a profit maximizing

\footnotetext{
${ }^{11}$ Assuming fixed retail prices simplifies the decision problem of the retailer as pricing is eliminated from his strategy set.

${ }^{12}$ For a competition policy discussion of time in the context of rebate schemes see MaierRigaud (2005).

${ }^{13}$ Due to the recursive nature of the problem over time solving for the expected profit maximizing stock at $\tau$ requires dynamic programming. We assume here that $q_{t}^{o}$ has been chosen in an optimal fashion for all $t \in\{1, \ldots, \tau-1\}$. Given the stochastic nature of the process, any arbitrary $\sum_{t=1}^{\tau-1} q_{t}^{o}$ could be the outcome of an optimal process, albeit with different probabilities.
} 
risk neutral retailer would want to have available. If the retailer chooses to remain in the rebate scheme, the optimal quantity $q_{R}^{*}>0$ the firm should keep available for serving demand is

$$
q_{R}^{*} \equiv \arg \max _{q_{R} \geq \hat{q}_{\tau}}\left[\begin{array}{r}
p^{*}\left(\int_{-\infty}^{q_{R}} x f(x) d x+q_{R} \int_{q_{R}}^{\infty} f(x) d x+\sum_{t=1}^{\tau-1} q_{t}\right) \\
-(1-\alpha) w\left(q_{R}+\sum_{t=1}^{\tau-1} q_{t}\right)
\end{array}\right]
$$

or

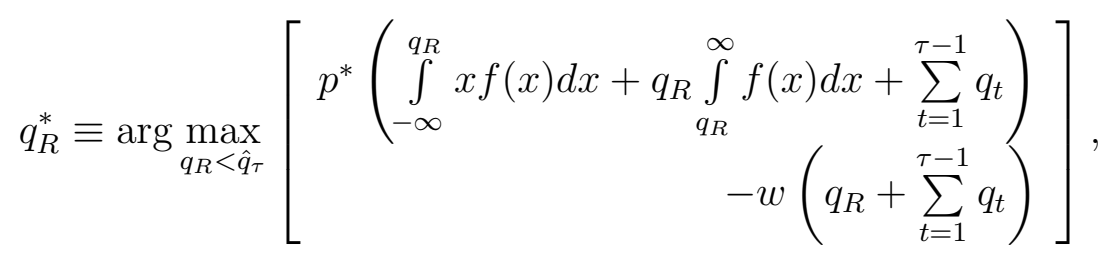

depending on whether

$$
\begin{gathered}
\max _{q_{R} \geq \hat{q}_{\tau}}\left[p^{*}\left(\int_{-\infty}^{q_{R}} x f(x) d x+q_{R} \int_{q_{R}}^{\infty} f(x) d x+\sum_{t=1}^{\tau-1} q_{t}\right)-(1-\alpha) w\left(q_{R}+\sum_{t=1}^{\tau-1} q_{t}\right)\right] \\
\sum_{q_{R}<\hat{q}_{\tau}}\left[p^{*}\left(\int_{-\infty}^{q_{R}} x f(x) d x+q_{R} \int_{q_{R}}^{\infty} f(x) d x+\sum_{t=1}^{\tau-1} q_{t}\right)-w\left(q_{R}+\sum_{t=1}^{\tau-1} q_{t}\right)\right] .
\end{gathered}
$$

Note that the latter case (equation 2) only arises if past sales were substantially lower than expected, that is, $\hat{q}_{\tau}$ is large $\left(\sum_{t=1}^{\tau-1} q_{t}\right.$ is small $)$ compared to the underlying distribution of potential expected sales. ${ }^{14}$

If the retailer decides to switch, the optimal quantity the firm should keep available for serving demand is

\footnotetext{
${ }^{14}$ Note that expected sales are potential as sales can only be made if sufficient quantity is held available.
} 


$$
q_{S}^{*} \equiv \arg \max _{q_{S}}\left[\begin{array}{r}
p^{*}\left(\int_{-\infty}^{q_{S}} x f(x) d x+q_{S} \int_{q_{S}}^{\infty} f(x) d x+\sum_{t=1}^{\tau-1} q_{t}\right) \\
-w\left(\sum_{t=1}^{\tau-1} q_{t}+s_{\tau}\right)-v\left(q_{S}-s_{\tau}\right)
\end{array}\right]
$$

Based on the optimal quantity ${ }^{15}$ (composed of the remaining stock plus newly bought quantities, i.e. $q_{R}^{*}=s_{\tau}+q_{\tau}^{o}$ ), expected profits given the retailer remains in the scheme ${ }^{16}$ is given by

$$
E(\pi \mid R) \equiv \begin{cases}p^{*}\left(\int_{-\infty}^{q_{R}^{*}} x f(x) d x+q_{R}^{*} \int_{q_{R}^{*}}^{\infty} f(x) d x+\sum_{t=1}^{\tau-1} q_{t}\right) & \\ -(1-\alpha) w\left(q_{R}^{*}+\sum_{t=1}^{\tau-1} q_{t}\right) & \text { if } q_{R}^{*} \geq \hat{q}_{\tau} \\ p^{*}\left(\int_{-\infty}^{q_{R}^{*}} x f(x) d x+q_{R}^{*} \int_{q_{R}^{*}}^{\infty} f(x) d x+\sum_{t=1}^{\tau-1} q_{t}\right) & \\ -w\left(q_{R}^{*}+\sum_{t=1}^{\tau-1} q_{t}\right) & \text { otherwise }\end{cases}
$$

where, given that $v=(1-\alpha) w$, it is trivial that the retailer would prefer to switch if $q_{R}^{*}<\hat{q}_{\tau}$ and therefore $E(\pi \mid R)$ is strictly dominated by $E(\pi \mid S)$ in the latter expression, and it is trivial that the retailer would prefer to remain if $q_{R}^{*}>\hat{q}_{\tau}$ and therefore $E(\pi \mid S)$ is strictly dominated by $E(\pi \mid R)$.

Expected profits given the retailer decides to switch to the linear pricing scheme offered by firm $B$ while planning the corresponding optimal quantity of $q_{S}^{*}=s_{\tau}+q_{\tau}^{o}$ is

${ }^{15}$ The analysis suggests that optimal orders and stocks are dependent on the variance of the distribution of expected sales, not only expected sales as such.

${ }^{16}$ We explicitly exclude the possibility of buying from both, firm $A$ and $B$ in $\tau$. In fact eliminating this option is only relevant if $v<(1-\alpha) w$, as the retailer would then strictly prefer firm $B$ for quantities above the threshold (if the remain option is optimal). As $v=(1-\alpha) w$, the retailer is indifferent between $A$ and $B$ for quantities above the threshold. 


$$
\begin{array}{r}
E(\pi \mid S) \equiv p^{*}\left(\int_{-\infty}^{q_{S}^{*}} x f(x) d x+q_{S}^{*} \int_{q_{S}^{*}}^{\infty} f(x) d x+\sum_{t=1}^{\tau-1} q_{t}\right) \\
-w\left(\sum_{t=1}^{\tau-1} q_{t}+s_{\tau}\right)-v\left(q_{S}^{*}-s_{\tau}\right)
\end{array}
$$

If $E(\pi \mid R)=E(\pi \mid S)$, the downstream firm is indifferent between $\mathrm{S}$ (switching supplier, i.e. choosing firm $B$ ) and $\mathrm{R}$ (remaining with the current firm, i.e. firm A).

Solving for $q_{\tau}^{o}$, we obtain the relevant switching threshold where the retailer is indifferent between schemes. The relevant numerical values based on the parameters used in the experiment will be presented in a later section together with a more detailed explanation.

\subsection{Boundedly rational behavior}

A classical example of "framing effects" 17 is the change from risk-averse to riskseeking behavior depending on whether the consequences of a decision problem (such as vaccination) are presented as a gain (200 of 600 threatened people will be saved) or as a loss (400 of 600 threatened people will die). ${ }^{18}$

Framing effects, however, are not simply the result of mistakes, i.e. unsystematic deviations around some true values, but are the result of systematic biases. Boundedly rational decision makers ${ }^{19}$ under- or overestimate certain decision op-

\footnotetext{
${ }^{17}$ See Tversky and Kahnemann (1981). Selten and Berg (1970) referred to such effects as presentation effects.

${ }^{18}$ Another framing effect concerns the order of play. Rapoport (1997), for example, has shown that sequential quantity decisions in a duopoly context push market shares towards the Stackelberg result even if these quantity decisions are not announced to the competitor and the game therefore remains isomorph to its simultaneous play version.

${ }^{19}$ The concept of bounded rationality was originally introduced by Simon (1955) with a view to the cognitive limitations of the human mind. At least since Selten (1978), the concept has broadened to encompass not only limitations of knowledge and computational capacity but genuinely different aspects such as motivation, adaptation and emotion.
} 
tions systematically (and predictably).

In the original formulation of prospect theory developed by Kahnemann and Tversky (1979), the term prospect referred to a lottery. Prospect theory suggests an explanation for framing effects, for example changes from risk-seeking to riskaverse behavior and vice versa, by assuming that the evaluations around losses and gains are based on a reference point.

According to prospect theory, the mapping of payoffs into utilities is not linear, but the value of gains or losses follows a nonlinear, "S"-shaped function (See Figure 1). The consequence is that decision makers who evaluate a decision framed as a loss will tend to take decisions that are risk-seeking.

Figure 1: Mapping of payoffs according to prospect theory. ${ }^{20}$

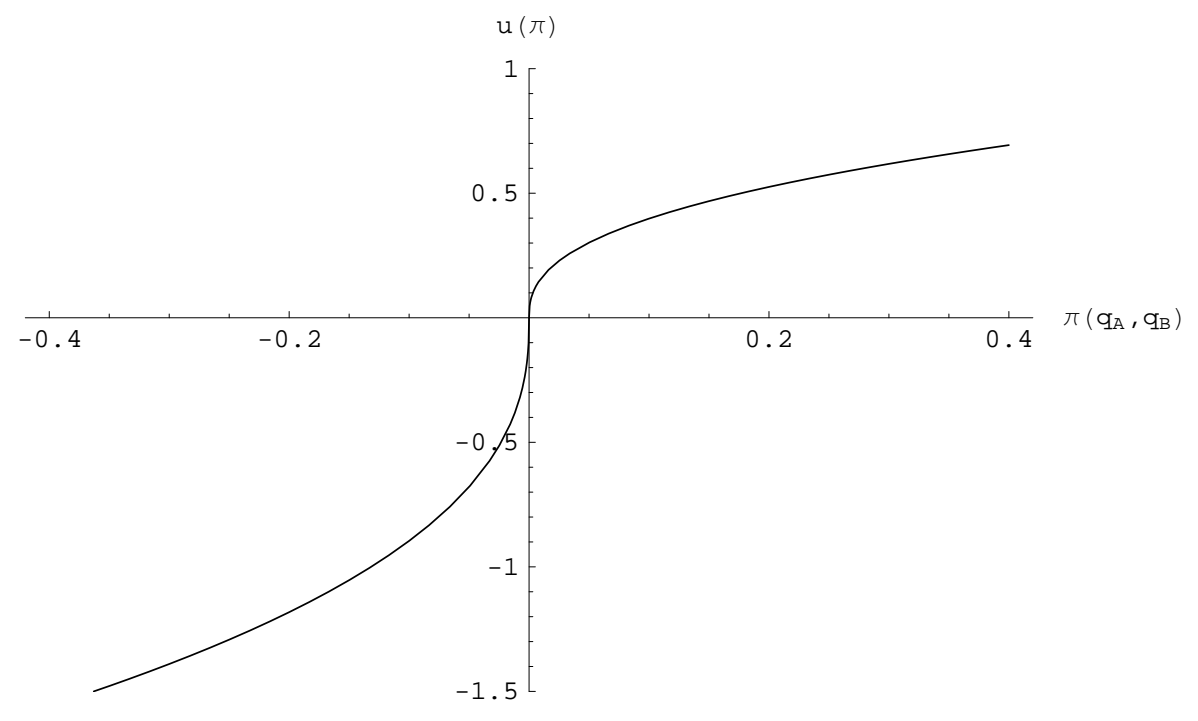

Prospect theory has been widely used in behavioral economics in order to explain a diverse range of situations that appear inconsistent with standard economic theory, such as the equity premium puzzle, the status quo bias, various gambling and betting puzzles, inter-temporal consumption and the endowment

\footnotetext{
${ }^{20}$ The function $u(\pi)$ gives the subjective payoffs and is given by $u(\pi) \equiv \pi^{\alpha}, \forall \pi \geq 0$ (win frame) and by $u(\pi) \equiv-\gamma\left(-\pi^{\beta}\right), \forall \pi<0$ (loss frame). The values of the parameters used in Figure 1 were $\alpha \equiv 0.4 \beta \equiv 0.4$ and $\gamma \equiv 2.25$.
} 
effect. It can also be used to derive predictions concerning switching behavior.

In the domain of marketing, Folkes and Wheat (1995) observed changes in the perception of prices in dependence of pricing schemes. Mowen and Mowen (1991) developed a model of time and outcome valuation (TOV) that incorporates both theoretic considerations and empirical results from prospect theory and approachavoidance-conflict theory (Miller (1959)). ${ }^{21}$ By integrating the latter, the impact of time on the valuation process in win- and loss-frames can be explained. TOV assumes that the "S"-shaped function of prospect theory flattens over time with different gradients in the win- and in the loss-frame. Therefore, according to TOV both losses and gains in the future are "discounted" compared to immediate gains and losses, with different discount rates respectively. TOV can be used to derive predictions concerning differences between rebates and discounts.

\section{The Experiment}

\subsection{Design}

The experiment was conducted at the experimental laboratory of the University of Bonn (BonnEconLab) using a computer program based on z-Tree (Fischbacher (1999)). A total of 118 students $(N=118$ independent observations) participated in the experiment. In all treatments participants were in the position of a retailer having to choose from what firm $(A$ or $B ; C$ or $B$ ) to procure and what quantity to procure for the fourth quarter, i.e. $\tau=4$. The fact that the quantity of the first three quarters had already been bought either from firm $A$ (offering a rebate scheme) or firm $C$ (offering a discount scheme) was imposed. ${ }^{22}$

\footnotetext{
${ }^{21}$ See also the empirical analysis by Juliusson et al. (2005) and Miller (1959).

${ }^{22}$ It is important to note that participants decided for the first time in the fourth quarter and that the decision for the first three quarters was attributed to another retail manager in the instructions and not to themselves. This presentation was explicitly chosen in order to reduce a possible confirmation or status quo bias (see for instance Samuelson and Zeckhauser (1988)) although such a bias can obviously not be excluded as the status quo bias may not only be based on cognitive dissonance.
} 
A table containing the highest possible sales quantities for the last 10 years was also available to the participants. This table was constructed according to the random variable $X$ (cf. footnote 9 ), i.e. the table was constructed from a censored normally distributed variable (as will be described below, one half of the participants received a table with low variance and the other half a table with high variance - the expected demand was held constant).

In order to ensure that participants orientate themselves according to this random model, they were also informed that demand for the product is season independent, but that there are differences in demand per year, and that their marketing research department expects a quarterly demand corresponding to our random model, i.e. 300 units (for further details see the translated instructions in Appendix A).

Altogether, participants were assigned to 10 different treatments. The treatments were based on three different experimental factors that were partially crossed over (Scheme-condition (REBATE, DISCOUNT) x Variance-condition (LOW, HIGH) x Switch-condition (STRONG REMAIN, WEAK REMAIN, SWITCH)).

The following table summarizes the design of the experiment composed of two main stages. Participants were split up in two different chronologies. Half of the participants were in a rebate scheme $(A)$ in the first stage and had to decide whether to switch to a linear scheme $(B)$. The other half of the participants began with a discount scheme $(C)$ and had to decide whether to switch to a linear scheme $(B)$. After this decision they had to decide about the quantity they wanted to buy. Once that choice was made, they were asked to make a quantity decision based on the counterfactual, i.e. what quantity they would have chosen if they had not decided to remain or switch. In the second stage participants were confronted with the respective other scheme, i.e. discount instead of rebate and rebate instead of discount.

The second experimental factor in our design was the variance of demand, 
Table 1: Overview of experimental treatments.

\begin{tabular}{c|ccc}
\hline treat. (n) & chronology & variance & optimal \\
\hline \hline $1(12)$ & AB-CB & High & strong Remain \\
$2(12)$ & AB-CB & High & weak Remain \\
$3(11)$ & AB-CB & Low & strong Remain \\
$4(11)$ & AB-CB & Low & Switch \\
$5(12)$ & AB-CB & High & Switch \\
$6(12)$ & CB-AB & High & strong Remain \\
$7(12)$ & CB-AB & High & weak Remain \\
$8(12)$ & CB-AB & High & Switch \\
$9(12)$ & CB-AB & Low & strong Remain \\
$10(12)$ & CB-AB & Low & Switch \\
\hline
\end{tabular}

i.e. the highest possible sales during the last ten years. In both, the high and low condition, the average was held constant. This was made possible by constructing the demand table with high variance out of the low variance table by multiplying the distance from the average over ten years (300 units) with the factor $2{ }^{23}$ For example, instead of 315 units in the fourth quarter 2005 in the low variance condition you find a value of 330 in the high variance condition.

The third experimental factor concerned the quantities of the first three quarters that were manipulated in such a way that it would either be rational to remain within the rebate or discount scheme, or to switch to the linear scheme.

In the first stage participants were confronted with the actual realized sales in the first three quarters. Based on the three different treatment conditions: either more than $\frac{2}{3}$ (strong remain, $\sum_{t=1}^{\tau-1} q_{t}=854$ ), exactly $\frac{2}{3}$ (weak remain, $\sum_{t=1}^{\tau-1} q_{t}=800$ ) or less than $\frac{2}{3}$ (switch, $\sum_{t=1}^{\tau-1} q_{t}=746$ ) of the total expected demand were sold in the first three quarters (and the rest was stocked).

If participants had chosen to continue to buy from the firm with the rebate

\footnotetext{
${ }^{23}$ Technically, such distributions can be created by taking standard-normalized values (with mean $=0$ and variance $=1$ ) and by transforming these $\mathrm{z}$-values by multiplying them with a constant $a$ and adding a constant $b$ in condition 1 and by multiplying with $a^{\prime}\left(a^{\prime}>a\right)$ and adding the constant $b$ in condition 2 . In our case, $a=25, a^{\prime}=50$ and $b=300$
} 
or discount scheme this implied that participants could either buy a sufficiently large quantity to meet the yearly threshold in order to get an overall unit price of $(1-\alpha) w=0.9$ or order a lower quantity entailing an overall unit price of $w=1$. If participants choose to switch to the firm with the linear scheme, they would pay $v \equiv(1-\alpha) w=0.9$ per unit for the quantity bought in the fourth quarter and $w=1$ for the quantity bought in the first three quarters.

After these two decisions ${ }^{24}$ were made participants were asked to decide upon a quantity in the counterfactual.

Following these decisions, a number was randomly drawn. The random process corresponded to the model underlying the distribution of demand in the quarters. The number drawn determined the maximum potential sales for the fourth quarter at price $p^{*}=1.5$. Participants were paid according to their decisions. If a higher quantity was bought than could be sold, the input costs were lost. If realized demand could not be met because an isufficiently high amount was bought, profits were foregone.

The second stage corresponded to the first stage, except for the scheme, that is, those in the rebate scheme were now in the discount scheme and vice versa.

The third stage of the experiment consisted in a measurement of risk preferences. $^{25}$

\subsection{Hypotheses}

Our central hypothesis (c.f. Hypothesis 1 below) is the expectation that participants in both rebate and discount schemes develop a status quo bias that a non-behaviorally informed standard economic theory would not predict. This 'status quo bias consists in a high reluctancy to quit rebate or discount schemes,

\footnotetext{
${ }^{24}$ The two decisions refer to the price scheme and the quantity decision.

${ }^{25}$ See Holt and Laury (2002). Since exactly the same instructions translated into German were used in order to elicit risk attitudes in the present experiment, we do not replicate the instructions here.
} 
even in the switch condition where it is rational to switch to the linear scheme. This expectation is based on the assumption that participants evaluate the situation as a sunk cost situation. If this assumption is adequate, a status quo bias in the discount and the rebate scheme that is due to the salience of the losses if the rebate scheme is left should be found. ${ }^{26}$

In addition to the central hypothesis, we expect a higher bias in the rebate condition compared to the discount scheme due to discounting effects of losses over time. ${ }^{27}$ In the following we will motivate these expectations, that can essentially be derived from prospect or any other theory that postulates a convex transformation of payoffs.

In our decision tasks, we conjecture that participants consider a negative payoff, i.e. the order payments. Therefore, we expect that participants are focussed on the loss-frame of the valuation function. ${ }^{28}$ In other words, we conjecture that participants focus on the prices that have to be paid. From this point of view the following situation is salient for the participants: Either to change from the rebate/discount scheme into a linear price scheme and thus incur "a loss" (i.e. an additional (negative) payment of 90 units) with certainty (the lost rebates/discounts for three quarters), or to stay in the rebate/discount scheme and maintain the possibility to reduce the payments. In both remain conditions this consideration is optimal, in the switch condition, however, this consideration results in suboptimal decisions.

\footnotetext{
${ }^{26}$ Note that this is likely to be more pronounced in the field than in our experiment where participants had no influence on sales. With the possibility to influence sales at a given price, the perception that the threshold is within reach may be further strengthened.

${ }^{27}$ Remember the framing difference between rebate and discount scheme, i.e. the respective risk of either not getting the rebate $(A)$ or having to pay back the discount already received $(C)$.

${ }^{28}$ It is misleading to tag this part of the valuation-function as "loss-frame". Prospect-theory maps payoffs on subjective valuations of these payoffs. Negative payoffs are not necessarily "losses". For example, investments can be analyzed with prospect theory as well, for instance in studies of the Concorde fallacy (sunk cost fallacy).
} 
Figure 2: Expected payoffs at the indifference point $\left(\sum_{t=1}^{\tau-1} q_{t}=784\right)$ in the low variance condition.

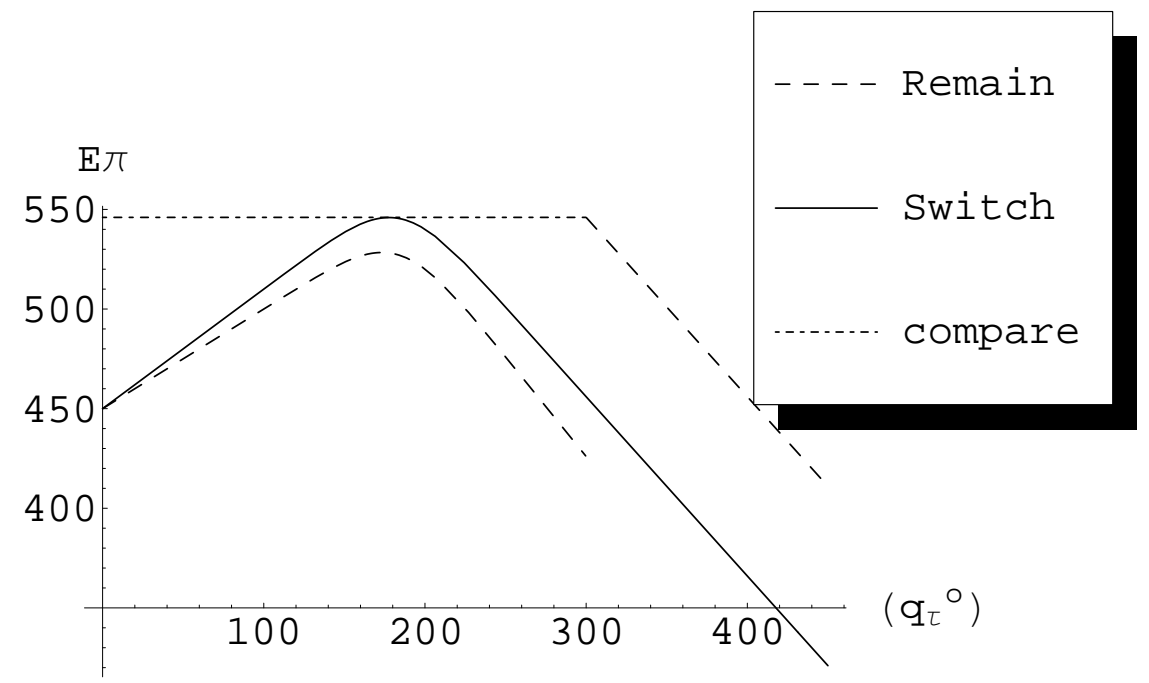

Both in rebate and in discount schemes participants have to compare the expected profits given they choose to remain in the rebate scheme with the profits in case of a switch to the linear price scheme. In our experiment the quantity to be ordered in $\tau$ depends only on the size of the stock in case of a switch as it is always optimal to purchase up to the threshold in the non-linear scheme. A salient difference between the linear price scheme and the rebate/discount scheme is that the decision to switch to $B$ is a decision that implies an additional cost of 90 (i.e. $0.1 \times 900$ ) with certainty. Furthermore, a switching decision allows to order the optimal quantity without regard to the threshold. In contrast, the decision to remain in the rebate/discount scheme corresponds to a decision, where the quantity ordered is not optimal but may allow higher profits through two channels. First, a higher quantity increases expected sales (this is due to the fact that at most the total available quantity can be sold) and second, the rebate/discount advantage over the quantity bought in the past is not lost. Now consider the point where expected profits in both schemes are equal, i.e. the 
indifference point. In our scenario this point corresponds to a quantity sold in the first three quarters of the year of $\sum_{t=1}^{\tau-1} q_{t}=784$ with $s_{\tau}=116$ for the low variance condition (see figure 2) and $\sum_{t=1}^{\tau-1} q_{t}=768$ with $s_{\tau}=132$ for the high variance condition (see figure 3). ${ }^{29}$ Both figures depict expected profits as a function of $q_{\tau}^{o}$. The continuous function in each figure depicts the expected profits under the linear scheme (i.e. implying a switch) and the function with the discontinuity at $q_{\tau}^{o}=300$ represents the expected profits under the rebate or discount scheme.

Figure 3: Expected payoffs at the indifference point $\left(\sum_{t=1}^{\tau-1} q_{t}=768\right)$ in the high variance condition.

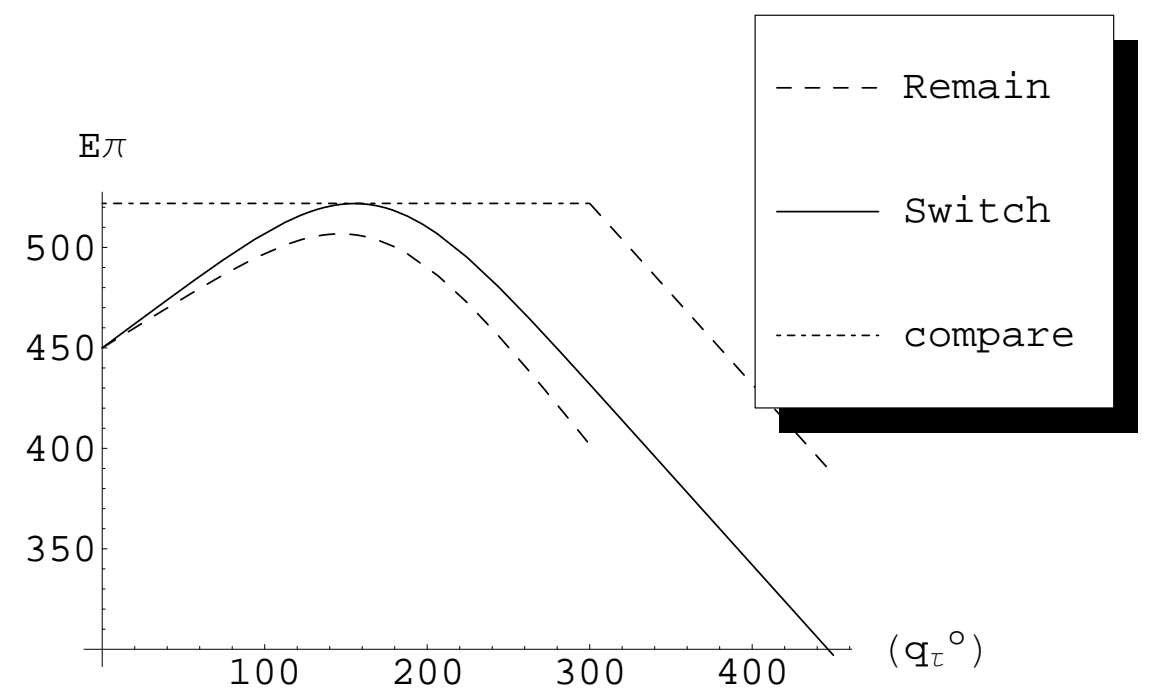

Due to identical expected profits at the indifference point, both options are on one and the same point of prospect theory's valuation function within the lossframe. ${ }^{30}$ The participant's decision to change into the linear price scheme, where

\footnotetext{
${ }^{29}$ The optimal $q_{\tau}^{o}$ is calculated by taking the derivative with respect to $q_{\tau}^{o}$ of equation 3 (note that $q_{R}^{*}=s_{\tau}+q_{\tau}^{o}$ ) as the optimal order quantity under the rebate scheme is always $q_{\tau}^{o}=300$ in this experiment. Inserting the optimal order quantities in both expected profit equations (2 and 3) and setting them equal yields the sales quantity $\sum_{\tau=1}^{\tau-1} q_{t}$ at which both schemes result in identical expected profits.

${ }^{30}$ In figure 2 expected profits in both schemes are 546 if the corresponding optimal quantities
} 
the optimal quantity to buy in the fourth quarter is always $q_{t}^{o}=294-s_{\tau}=178$ for the low variance condition and $q_{t}^{o}=287-s_{\tau}=155$ for the high variance condition, is also a decision to incur a loss with certainty. In this case, the sunk costs are eliminated and an optimal quantity for the fourth quarter can be planned. However, the participants decision to remain in the rebate/discount scheme leaves a chance to reduce the losses. Figure 4 gives the two cumulative density functions for the expected losses in case of remaining in the rebate scheme versus switching if the optimal quantities are purchased (high variance condition). Expected profits are 522 under both schemes.

Figure 4: Choice at the indifference point under the high variance condition. ${ }^{31}$

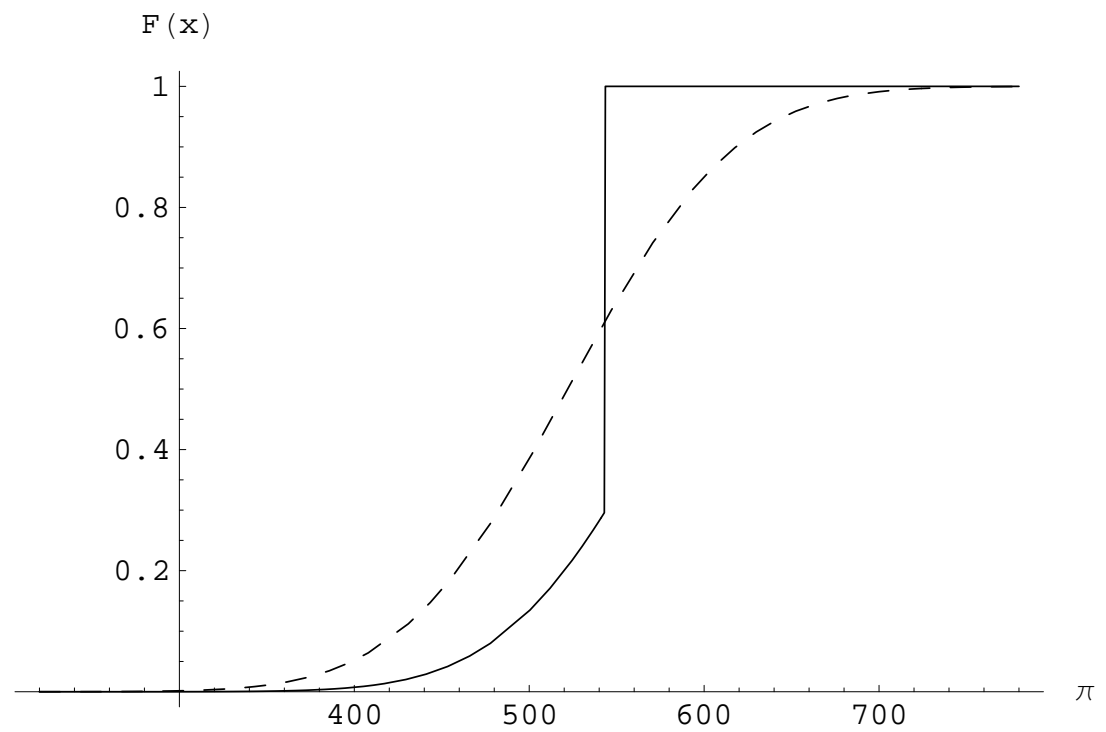

Thus, our experiment gives an interesting extension of classic lottery experiments, because the choice to remain in the rebate/discount scheme does not merely consist in either paying a fixed amount with probability $\rho$ or paying another fixed value with probability $1-\rho$, but that both the area of lower profits are purchased. In figure 3, expected profits are 522 .

${ }^{31}$ The solid cumulative density function represents the linear price scheme. It jumps at 543 . The area under this cumulative density function to the left of 543 is 0.4 and 0.6 to the right. The dashed cumulative density function represents the non-linear scheme. 
and the area of higher profits are partly continuously distributed.

Hypothesis 1: In line with prospect theory we expect risk-seeking behavior at the indifference point, because losses loom larger than gains. Therefore, given two price schemes $A$ (or $C$ ) and $B$ such that rational actors should be indifferent between the two options, we expect a preference for choosing option $A$ or $C$ the rebate or discount scheme - because in this case losses (i.e. a higher price for the units of the first quarters) have not yet been realized and the chance to compensate losses by gains is maintained. We expect that this tendency is strong enough to find a reluctancy to switch to the linear price scheme even if this were the optimal choice. In other words, we expect that a substantial proportion of participants in the switch condition remain within the rebate or discount scheme, although this is not an optimal choice and that this proportion is above a common error level. We also expect that participants in the two remain conditions have a strong tendency to remain in the rebate or discount scheme.

The analysis so far does not allow distinct predictions for rebate and discount schemes. The analysis is also independent of the exact point participants focus on as long as they are in the "loss-frame". This makes our predictions rather general and robust against differences in anchors. Our interpretation of prospect theory's valuation function is non-parametric and does, therefore, not entail any estimation of parameters. ${ }^{32}$ As a result, any arbitrary convex transformation of payoffs would yield the same predictions.

Hypothesis 2: The following hypothesis is much more sensitive with respect to foci (i.e. salient features) that are set within the instruction set. It is derived from the TOV model due to Mowen and Mowen (1991) who conjecture that both, gains and losses are discounted over time. As a consequence, the moment in time where losses are realized is relevant. According to our time framing hypothesis we expect stronger effects in rebate than in discount schemes because in the former

\footnotetext{
${ }^{32} \mathrm{We}$ only need the properties of the shape of the function not its functional form.
} 
losses are immediate, whereas in the latter there is a time lag between the decision and the loss. ${ }^{33}$ In other words, the price $v \equiv(1-\alpha) w$ is paid right from the start in discount schemes whereas in rebate schemes a price $w>v$ is paid.

An alternative explanation could postulate different anchors of discount compared to rebate schemes within the valuation function of prospect theory. In this case, the assumption is that in case of the rebate scheme the participants have invested to earn the rebate. This would be sunk costs and this is why they should stick to their earlier decision, whereas in case of the discount scheme they risk an additional out of pocket payment. This should lead to risk-averse behavior and higher orders. Based on our setting, such different anchors are implausible, because we tried to prevent the sunk-cost-phenomenon as much as possible by instructing participants that they are new in the firm and make their decision for the first time (cf. footnote 22). Furthermore, this hypothesis does not imply an exact prediction of the strength of the effects of the discount-scheme compared to the rebate-scheme, because in both cases participants should buy more and the loss aversion in case of the discount-scheme should lead - seemingly paradoxically - to risk-seeking behavior, i.e. increased orders to prevent from losses. In summary, this type of explanation postulates two different mechanisms that are at work in case of the discount-scheme compared to the rebate-scheme, but both mechanisms lead to similar effects and estimating such effects requires an exact parametrization of the mechanisms. On the other hand, TOV allows clear comparisons between rebate and discount schemes and makes clear predictions. We expected corresponding effects in our experiment.

Hypothesis 3: Besides the hypotheses mentioned above, we were also tentatively interested in the influences of risk-seeking and risk-averse behavior in such price schemes. Therefore, we introduced an experimental variation of variances.

\footnotetext{
${ }^{33}$ Note, that although this time lag might be relevant in practice, in our experiment this lag consisted in 1) the understanding of the instructions and thus the imagined time lag and 2) in a minimal lag in the discount condition because the loss is not immediate but only becomes apparent with the next feedback form the participant receives.
} 
We also used a test that measures risk attitudes. Measuring risk preferences is also important from a theoretical point of view because neoclassical theory now typically involves conditional predictions that depend on risk attitudes. ${ }^{34}$ Due to the fact that higher variances incorporate higher risks we should find some differences between the situation with a high variance compared to the situation with a low variance, because risk-aversion should be more pronounced in the situation with a high variance.

\subsection{Experimental Results}

Besides the general confirmation of our hypotheses we found a high amount of suboptimal decision making, leading to a high "noise"-rate. Given the complexity of the task, this is not overly surprising. The total error rate of suboptimal switches (instead of remaining) and suboptimal remaining (instead of switching) is $29 \%(N=118)$ in the first stage, $27 \%(N=118)$ in the second stage and $28.0 \%(N=236)$ overall. ${ }^{35}$ Considering participants that at any moment during the experiment either remained in the non-linear scheme and ordered less than 300 or switched and ordered more than 300, as inconsistent, 26 participants of 118 fall in that category.

Our central hypothesis concerns status quo biases created by rebate or discount schemes. In the weak remain condition we found only $22.9 \%(N=48)$ who switch to a linear price scheme while in the strong remain condition only $21.3 \%$ ( $N=94)$ switched (pooled over both stages). Furthermore, we expected that

\footnotetext{
${ }^{34}$ It is not clear, however, whether such attitudes should be understood as a personal trait or as a disposition mostly triggered by the situation (i.e. a personal state).

${ }^{35} \mathrm{In}$ a follow up study we would adapt our instructions by making it more salient that there may be good contextual reasons for the order strategies of the predecessor such as capacity constraints or simply that it was reasonable to order from $A / C$ because the alternative firm could not offer this price from the beginning. Ex post we believe that some of our participants may have been irritated by the fact that the alternative firm offers the same price without any further conditions for the fourth quarter and that no plausible explanation for the ordering behavior in the previous quarters was given. If this conjecture is right, reactance may have caused at least part of the high noise-rate.
} 
the error rate is even higher in those cases where it would be optimal to switch from a rebate or discount scheme into the linear price scheme. Indeed, in this case $37.2 \%$ of all $(N=94)$ participants remained in the rebate/discount scheme although it would have been optimal to switch to the linear price scheme.

Result 1: Testing the independence of the rates of optimal or suboptimal behavior and the switch-conditions (where it is either optimal to stay or optimal to switch) pooled over all switch-conditions separately yields ( $p \leq 0.051$; onesided) in the first stage and ( $p \leq 0.051$; one-sided) in the second stage using a Fisher exact test. Pooling both stages of the experiment yields a significant result $\left(p \leq 0.008\right.$; one-sided). ${ }^{36}$ A more detailed analysis of the switch conditions comparing strong remain vs. switch in the first stage yields a significant result ( $p \leq 0.018$; one-sided) and pooled over both stages ( $p \leq 0.012$; one-sided $)$. Therefore, it could be demonstrated that besides the high error rates that can be observed in our scenario we find a status quo bias that keeps participants from switching into the linear scheme.

Result 2: Although we could also find a higher "attraction" effect within the rebate condition compared to the discount condition $(40.4 \%$ versus $34.0 \%$, $N=47$ respectively), this difference was not significant $\left(\chi^{2}=0.18 ; p \leq 0.6696\right.$; $N=94)$.

Result 3: A closer look at the variance conditions also yielded the interesting result, that the significance of rebate or discount "attraction" was mainly produced in the high variance condition. Whereas the status quo bias is significant with high variances $\left(\chi^{2}=5.67 ; p \leq 0.0172 ; N=144\right)$, it is not significant for the low variance condition $\left(\chi^{2}=0.93 ; p \leq 0.3355 ; N=92\right)$. This could be attributed to the fact that a higher available quantity is subjectively perceived as being more attractive under high variance of demand because it reduces the perceived risk of not being able to fully serve demand.

\footnotetext{
${ }^{36} \mathrm{~A}$ corresponding $\chi^{2}$-test yields $\left(\chi^{2}=5.92 ; p \leq 0.010 ; N=236\right)$.
} 
Result 4: With respect to risk preferences, we were unable to find any correlation between decisions in the main experiment and the particular risk attitude test applied, suggesting that risk preferences are a state rather than a personal trait.

\section{Conclusion}

In the experiment conducted we found that discount and rebate schemes as defined in this paper exert a significant "attraction" on participants. This status quo bias is in line with prospect theory or any alternative theory that postulates a convex transformation of payoffs.

The experimental findings presented indicate that standard economic theory relying on risk neutral profit maximizing behavior tends to underestimate the effects of rebate and discount schemes on customer behavior. This is in line with recent experimental findings in Operations Research analyzing single period stochastic inventory problems. In the experimental literature on the newsvendor problem with low profit products procurement quantities were also found to be higher than expected profit maximizing quantities.

Concerning the external validity of these findings one has to bear in mind, for example, that the analysis focusses on individual decision-making whereas decisions in firms are typically the outcome of a corporate decision-making process. Whether a corporate decision-making process improves or reduces "rationality" remains highly debated in the literature and appears to depend largely on the exact circumstances of the process. Based on the strength of the effects found, we would, however, be surprised not to encounter similar decision patterns in a corporate environment.

Finally, we believe that part of the recent surge in non-linear pricing especially in relations with non-professional buyers may be due to the behavioral effects identified in this paper. If empirical evidence of a status quo bias in cer- 
tain non-linear pricing schemes is further corroborated, such effects may not only play an important role in the design of pricing schemes but should also be taken into account in the design of consumer protection and competition policy. An interesting extension of this paper would be to experimentally distinguish between a (possibly less pronounced) status quo bias in a linear scheme versus the "attraction" exerted by the non-linear schemes discussed. 


\section{References}

Arrow, K., Harris, T., and Marschak, J. (1951). Optimal inventory policy. Econometrica, 19:250-272.

Beckenkamp, M. and Maier-Rigaud, F. P. (2006). An experimental investigation of Article 82 rebates. Competition Law Review, 2(2):1-31.

Ben-Zion, U., Cohen, Y., Peled, R., and Shavit, T. (2005). Decision-making and the newsvendor problem - an experimental study. Discussion paper.

Bolton, G. E. and Katok, E. (2005). Learning-by-doing in the newsvendor problem. Discussion paper, Penn State University.

Brown, A. O. and Tang, C. S. (2000). Decisions, operations, and technology management. Discussion Paper CT30, UCLA, Anderson Graduate School of Management.

Davis, D. D. (2006). Rebate subsidies, matching subsidies and isolation effects. Judgement and Decision Making, 1(1):13-22.

Davis, D. D. and Millner, E. L. (2005). Rebates, matches, and consumer behavior. Southern Economic Journal, 72(2):410-421.

Davis, D. D., Millner, E. L., and Reilly, R. J. (2005). Subsidy schemes and charitable contributions: A closer look. Experimental Economics, 8:85-106.

Eckel, C. C. and Grossman, P. J. (2003). Rebates vs. matching: Does how we subsidize charitable contributions matter? Journal of Public Economics, 87:681-701.

Eckel, C. C. and Grossman, P. J. (2006). Subsidizing charitable giving with rebates or matching: Further laboratory evidence. Southern Economic Journal, 72(4):794807.

Fischbacher, U. (1999). Z-tree. Zürich toolbox for readymade economic experiments. Discussion paper, University of Zürich.

Folkes, V. and Wheat, R. (1995). Consumers' price perceptions of promoted products. Journal of Retailing, 71:317-328.

Holt, C. and Laury, S. (2002). Risk aversion and incentive effects. American Economic Review, 92:1644-1655.

Juliusson, E., Karlsson, N., and Gärling, T. (2005). Weighing the past and the future in decision making. European Journal of Cognitive Psychology, 17:561-575.

Kahnemann, D. and Tversky, A. (1979). Prospect theory: An analysis of decision under risk. Econometrica, 47:263-292.

Karlan, D. and List, J. A. (2006). Does price matter in charitable giving? evidence from a large scale natural field experiment. Discussion Paper 12338, NBER. 
Katok, E., Thomas, D., and Davis, A. M. (2006). Inventory service level agreements as coordination mechanisms: The effect of review periods.

Lurie, N. H. and Swaminathan, J. M. (2005). Is timely information always better? the effect of feedback frequency on performance and knowledge acquisition. Discussion paper, University of North Carolina at Chapel Hill.

Maier-Rigaud, F. (2005). Switchings Costs in Retroactive Rebates - What's time got to do with it? European Competition Law Review, 26(5):272-276.

Maier-Rigaud, F. (2006). Article 82 rebates: Four common fallacies. European Competition Journal, 2(2):85-100.

Miller, N. (1959). Liberalization of Basic S-R Concepts: Extensions to Conflict Behavior, Motivation, and Social Learning. In Koch, S., editor, Psychology: The Study of a Science, pages 196-292. McGraw-Hill New York.

Mills, E. S. (1959). Uncertainty and price theory. Quarterly Journal of Economics, $73: 116-130$.

Mowen, J. and Mowen, M. (1991). Time and outcome valuation: Implications for marketing decision making. Journal of Marketing, 55:54-62.

Petruzzi, N. C. and Dada, M. (1999). Pricing and the newsvendor problem: A review with extensions. Operations Research, 47(2):183-194.

Porteus, E. L. (1990). Stochastic inventory theory. In Heyman, D. P. and Sobel, M. J., editors, Handbooks in OR and MS, volume 2, pages 605-652. Elsevier, NorthHolland.

Rapoport, A. (1997). Order of play in strategically equivalent games in extensive form. International Journal of Game Theory, 26:113-136.

Samuelson, W. and Zeckhauser, R. (1988). Status quo bias in decision making. Journal of Risk and Uncertainty, 1(1):7-59.

Schweitzer, M. E. and Cachon, G. P. (2000). Decision bias in the newsvendor problem with a known demand distribution: Experimental evidence. Management Science, 46(3):404-420.

Selten, R. (1978). The chain store paradox. Theory and Decision, 9:159-172.

Selten, R. and Berg, C. (1970). Drei experimentelle Oligopolspielserien mit kontinuierlichem Zeitablauf. In Sauermann, H., editor, Beiträge zur experimentellen Wirtschaftsforschung II, pages 162-221. Mohr, Tübingen.

Simon, H. (1955). A behavioral model of rational choice. Quarterly Journal of Economics, 69:99-118.

Tversky, A. and Kahnemann, D. (1981). The framing of decisions and the psychology of choice. Science, 211:453-458. 


\section{APPENDIX A}

[all $]$

\section{INSTRUCTIONS}

In the following experiment you will be in the role of a newly hired procurement manager of a retailer for the year 2005. This retailer sells a product of daily use. The sales of the product are not subject to seasonal fluctuations. There are no indications for changes in the market. Your role consists in generating profits for the retailer in the year 2005. Your sales price is fixed at 1,50 ECU. Your remuneration in this experiment is based on the profits of the retailer transformed into Euro based on an exchange rate. Given that the sales price is given, the procurement price (see section I) and the sales quantity (see section II) is crucial in determining profits.

\section{PROCUREMENT}

[Instructions CB only]

You have the choice between firm $\mathrm{C}$ and firm $\mathrm{B}$ to procure the product. Firm $\mathrm{C}$ offers a discount of $10 \%$ and $\mathrm{B}$ offers a constant price.

Firm $\mathrm{C}$ offers the following discount: The discounted price per unit is 0,90 ECU. If you procure at least 1200 units from that firm within the year, you do not have to repay the discount of 0,10 ECU per unit, that you would otherwise have to repay for every unit received at discounted price.

[Instructions AB only]

You have the choice between firm A and firm B to procure the product. Firm A offers a rebate of $10 \%$ and B offers a constant price.

Firm A offers the following rebate: The price per unit is 1,00 ECU. If you procure at least 1200 units from that firm within the year, you receive a rebate of 0,10 ECU per unit for all units bought within the year, otherwise your price remains at 1,00 ECU per unit.

[all]

Firm B offers the following price: Irrespective of the quantity you procure within the year, you always pay 0,90 ECU per unit.

As new manager of procurement in your retail company, you decide for the first time in the 4th quarter 2005 from what company you would like to order and how many units you would like to order. For your decision it is important to note that 900 units where bought from

[Instructions CB only]

Firm $\mathrm{C}$ in the first three quarters at the preliminary price of $0,90 \mathrm{ECU}$.

Examples: 
- If you decide to procure 300 units from firm $\mathrm{C}$ in the 4 th quarter, you pay $270 \mathrm{ECU}$ for the last 300 units. For the total year, you have procured 1200 units and paid 1080 ECU.

- If you decide to procure 300 units from firm B in the 4th quarter, you pay 270 ECU for the last 300 units. Since overall you bought less than 1200 units from firm C, you have to repay the discount of 90 ECU to firm C. For the total year, you have paid 1170 ECU.

- If you decide to procure 150 units from firm $\mathrm{C}$ in the 4th quarter, you pay 135 ECU for the last 150 units. Since overall you bought less than 1200 units from firm C, you have to repay the discount of 105 ECU to firm C. For the total year, you have paid 1050 ECU.

- If you decide to procure 150 units from firm B in the 4th quarter, you pay $135 \mathrm{ECU}$ for the last 150 units. Since overall you bought less than 1200 units from firm C, you have to repay the discount of 90 ECU to firm C. For the total year, you have paid 1035 ECU.

[Instructions AB only]

Firm $\mathrm{A}$ in the first three quarters at the preliminary price of 1 ECU.

Examples:

- If you decide to procure 300 units from firm $\mathrm{A}$ in the 4 th quarter, you pay $300 \mathrm{ECU}$ for the last 300 units minus the rebate of $10 \%$ on all 1200 units. This is a rebate of 120 ECU. As a result you have to pay $180 \mathrm{ECU}$ for the 300 units bought in the 4th quarter. For the total year, you have procured 1200 units and paid 1080 ECU.

- If you decide to procure 300 units from firm B in the 4th quarter, you pay 270 ECU for the last 300 units. Since overall you bought less than 1200 units from firm A, do not qualify for the rebate. For the total year, you have paid 1170 ECU.

- If you decide to procure 150 units from firm $\mathrm{A}$ in the 4th quarter, you pay $150 \mathrm{ECU}$ for the last 150 units. Since overall you bought less than 1200 units from firm A, you do not qualify for the rebate offered. For the total year, you have paid 1050 ECU.

- If you decide to procure 150 units from firm B in the 4th quarter, you pay $135 \mathrm{ECU}$ for the last 150 units. Since overall you bought less than 1200 units from firm A, you do not qualify for the rebate offered. For the total year, you have paid 1035 ECU.

[all]

\section{SALES}

As procurement manager you have to estimate how many units you will be able to sell and procure units accordingly. In the appendix you find quarterly demand information of the last 10 years. During the experiment you 
will receive the sales information of the first three quarters of 2005. After your decision you will be informed about demand in the fourth quarter. As mentioned before, 900 units have been procured in the first three quarters of 2005. This corresponds to 300 units per quarter as calculated by your market research department. Despite demand fluctuations in every quarter demand is expected to be 300 units on average per quarter. Your market research department could not identify seasonal fluctuations and there exists no pattern in yearly fluctuations either. Concerning your quarterly demand, you should therefore orient yourself on a sales volume of 300 units irrespective of any information. At the beginning of 2005 your stocks were empty. If demand in the first three quarters was below 900 units you have stocks. It is now your task to decide from what firm to buy and how many units to buy there based on information on sales and current stocks

\section{PROFIT CALCULATION}

Profit is calculated from yearly procurement and sales. The number of sold units is multiplied with the sales price of 1,50 ECU. In order to obtain the profits, the costs of all procurement are deducted from that amount. Positive stocks are lost at the end of the 4th quarter.

If you do not have any further questions, please click on START. You will then be asked to fill out control questions

Once you have answered the control questions, please wait until the experiment is started.

The sales situation in the last 10 years was: 
[all High Variance]

\begin{tabular}{|c|c|c|}
\hline year & quarter & demand (highest possible sales) \\
\hline \multirow[t]{4}{*}{1996} & 1 & 276 \\
\hline & 2 & 54 \\
\hline & 3 & 540 \\
\hline & 4 & 30 \\
\hline \multirow[t]{4}{*}{1997} & 1 & 126 \\
\hline & 2 & 252 \\
\hline & 3 & 552 \\
\hline & 4 & 192 \\
\hline \multirow[t]{4}{*}{1998} & 1 & 474 \\
\hline & 2 & 54 \\
\hline & 3 & 336 \\
\hline & 4 & 570 \\
\hline \multirow[t]{4}{*}{1999} & 1 & 90 \\
\hline & 2 & 210 \\
\hline & 3 & 324 \\
\hline & 4 & 132 \\
\hline \multirow[t]{4}{*}{2000} & 1 & 504 \\
\hline & 2 & 540 \\
\hline & 3 & 366 \\
\hline & 4 & 228 \\
\hline \multirow[t]{4}{*}{2001} & 1 & 462 \\
\hline & 2 & 420 \\
\hline & 3 & 288 \\
\hline & 4 & 228 \\
\hline \multirow[t]{4}{*}{2002} & 1 & 582 \\
\hline & 2 & 312 \\
\hline & 3 & 282 \\
\hline & 4 & 360 \\
\hline \multirow[t]{4}{*}{2003} & 1 & 492 \\
\hline & 2 & 438 \\
\hline & 3 & 0 \\
\hline & 4 & 378 \\
\hline \multirow[t]{4}{*}{2004} & 1 & 18 \\
\hline & 2 & 336 \\
\hline & 3 & 360 \\
\hline & 4 & 330 \\
\hline
\end{tabular}


[all Low Variance]

\begin{tabular}{|c|c|c|}
\hline year & quarter & demand (highest possible sales) \\
\hline \multirow[t]{4}{*}{1996} & 1 & 288 \\
\hline & 2 & 177 \\
\hline & 3 & 420 \\
\hline & 4 & 165 \\
\hline \multirow[t]{4}{*}{1997} & 1 & 213 \\
\hline & 2 & 276 \\
\hline & 3 & 426 \\
\hline & 4 & 246 \\
\hline \multirow[t]{4}{*}{1998} & 1 & 387 \\
\hline & 2 & 177 \\
\hline & 3 & 318 \\
\hline & 4 & 435 \\
\hline \multirow[t]{4}{*}{1999} & 1 & 195 \\
\hline & 2 & 255 \\
\hline & 3 & 312 \\
\hline & 4 & 216 \\
\hline \multirow[t]{4}{*}{2000} & 1 & 402 \\
\hline & 2 & 420 \\
\hline & 3 & 333 \\
\hline & 4 & 264 \\
\hline \multirow[t]{4}{*}{2001} & 1 & 381 \\
\hline & 2 & 360 \\
\hline & 3 & 294 \\
\hline & 4 & 264 \\
\hline \multirow[t]{4}{*}{2002} & 1 & 381 \\
\hline & 2 & 360 \\
\hline & 3 & 294 \\
\hline & 4 & 264 \\
\hline \multirow[t]{4}{*}{2003} & 1 & 396 \\
\hline & 2 & 369 \\
\hline & 3 & 150 \\
\hline & 4 & 339 \\
\hline \multirow[t]{4}{*}{2004} & 1 & 159 \\
\hline & 2 & 318 \\
\hline & 3 & 330 \\
\hline & 4 & 315 \\
\hline
\end{tabular}

